\title{
Stepping up to adult services
}

\author{
Moving from children's to adults' services can be difficult. Lucy Watts discusses what might have \\ made her transition smoother
}

\author{
Lucy Watts
}

I was born with a complex, life limiting condition. At 14 I became disabled, and at $15 \mathrm{I}$ had started tube feeding, which was a big adjustment. I desperately needed support. A few weeks after my 16th birthday, my mother and I arrived at hospital for what I thought would be another routine appointment with my paediatrician. At that meeting I was told that because of my age I was being discharged from children's services. As I was wheeled out of that appointment I felt I was no longer a paediatric patient but not yet an adult. It seemed as if I had no team to take over my care; what was I going to do?

\section{Sudden change}

The shock was immense. As a paediatric patient, I relied on my mother to do all the phoning, liaising, and advocacy that ensured I got the care and support I required. Inpatient admissions took place on a paediatric ward where my mother could stay with me-making decisions with me, supporting me, and providing much of my care. Even though I was 14 when I became seriously ill, I don't remember discussions about transition to adult care. Suddenly, I was being asked to advocate for myself and manage the coordination and organisation of my care, but I didn't feel that I had the support to be able to answer the questions.

\section{The adult ward}

The differences between paediatric wards and adult wards proved even more traumatic. At 17 years old, I found myself on a ward with five patients who had dementia and who cried and yelled much of the time. My mother was only allowed in at visiting times, so I had to make important decisions on my own. I had to sign my own consent forms for the first time. I felt alone and scared. I had no television, internet connection, or radio signal, and I was unable to leave the ward. I couldn't do anything independently and I couldn't escape.

\section{What would have helped}

So what did I need to make my transition better? Firstly, I needed the process to have started earlier-from when I first became seriously ill at 14 and it was clear I would need long term care-and the change needed to be taken at my own pace.
Secondly, I needed a transitional care plan developed with me and my mother and coordinated by a consultant, specialist, community nurse, or family doctor.

Children undergoing this transition need support to empower them to step up when able and take charge of their health and care, and for parents to step back when applicable.

During consultations, health professionals might ask parents to step out for some of or all of the appointment to enable young patients to get used to consulting alone. This might help young patients to learn advocacy for themselves and for parents to learn how to let their emerging adult child take the lead. Peer support groups and mentoring-face to face or via social media, Skype, telephone, email, or text message — can help build these skills. Putting young adults in contact with patients who have already made the transition to adult services allows them to exchange experiences and mentors to offer guidance.

For me, like other people with complex, intensive needs, it would have been helpful to have had a parent stay in hospital —or at least to have been asked if I wanted to have a parent there for ward rounds and other important parts of admission. Being put in a side room would have prevented me from hearing the distressing noises of the patients with dementia. When I was 17 the staff of the young adult hospice began to support me and they taught me crucial skills in self advocacy. They appreciated my desire to have my mother involved and treated me like an adult, but they understood that I was inexperienced, vulnerable, and scared. They checked to see that I wasn't overwhelmed and asked what my wishes were-for example, did I want my mother present? Would I like to speak about this without her? They saw the big picture and it helped me.

Transition is a process, not a single event. When done right it sets the scene for a young person's care in adult services. When it is done wrong a young patient might not be able to cope and may even disengage from services. Becoming an adult is a process that continues over years. Young adults aren't big children nor are they little adults; they are a unique subgroup of the population and need to be treated as such. 


\section{What you need to know}

- Transition is a process, not a single event, and it takes time, planning, support, and children's and adults' services working together

- Stepping up is a process that takes time; you must be prepared and support young people with the shift in responsibility

- Try to establish how much responsibility a young person might want or can manage, and be gentle with them if they struggle

\section{Education into practice}

- How have you been involved in the care of young people as they move from children's to adults' services? Can you think of situations where this has gone well and not so well? What themes link these examples?

What insights or ideas does this article offer you on what might be important to young people in this transition?

-How do you think you could better support young people to move from children's to adults' services?

These questions were developed by the editors and reviewed by the patient author

\section{Further information}

Stepping up by Together for Short Liveswww.togetherforshortlives.org. uk/

Transition checklist by Together for Short Lives www.togetherforshortlives. org.uk/changing-lives/developing-services/transition-adult-services/

National Institute for Health and Care Excellence. Guidance: transition from children's to adults' services for young people using health or social care services www.nice.org.uk/guidance/ng43

Singh SP, Anderson B, Liabo K, et al. Supporting young people in their transition to adults' services: summary of NICE guidance. BMJ 2016;353:i2225, doi:10.1136/bmj.i2225

Competing interests: I have read and understood BMJ policy on declaration of interests and declare the following: LW is an independent consultant for the Worldwide Hospice Palliative Care Alliance and a trustee for the Pseudo Obstruction Research Trust, sits on two Transition Taskforce Regional Action Groups, and is presenting at the Hospice UK Conference in November 2018 on transition, young adulthood, and sexuality.

Provenance and peer review: Commissioned, based on an idea from the author; not externally peer reviewed.

Published by the BMJ Publishing Group Limited. For permission to use (where not already granted under a licence) please go to http://group.bmj.com/group/rights-licensing/ permissions 